\title{
THE EXPORT OF BRAZILIAN WORKERS TO THE U.S.: FROM WORK TO LIVE TO LIVE TO WORK
}

Eduardo Siqueira

Corresponding author: Eduardo Siqueira - carlos.siqueira@umb.edu PhD. Professor at the College of Public and Community Service, Coordinator of the Transnational Brazilian Project at The Mauricio Gastón Institute for Latino Community Development and Public Policy, University of Massachusetts. Boston, Massachusetts, The United States.

Hundreds of thousands of Brazilians have emigrated to the U.S for over thirty years now ${ }^{1-3}$. While the size of the population, civil status, gender, sending and receiving, and socioeconomic position of emigrants have varied over the decades, the majority of Brazilian e/immigrants to the U.S. always claimed that they had to leave Brazil, at least temporarily, to improve their living conditions. These émigrés were optimistic that life in the U.S would be better because they would make more money, buy state of the art consumer products, send remittances to family members, live in good apartments or houses located in safe neighborhoods, and provide good education and health for their children. In contrast, other Brazilians left their homeland to escape from conditions such as domestic violence, community violence, and sexual oppression, wherein family and community life were sources of intense suffering and stress, if not life threatening.

This "Brazilian immigrant dream" assumed that since socioeconomic conditions in a third world country, such as Brazil, were bad when they left, they certainly would be better off in a first world, wealthy country such as the U.S. Unfortunately, most Brazilians did not realize, as they left the "Santa Terrinha," that they had actually become "superfluous" labor as a result of decades of successive neoliberal macroeconomic crises that created unemployment, low wages, social unrest, and violence, among many other negative social impacts. Societal forces beyond their control could have driven a massive Brazilian emigration to the U.S. Yet, despite these strong "push" factors, only a fraction of those affected by the crises decided to pursue the risky journey to Florida, Massachusetts, New York, New Jersey, or California, among other U.S states.

I wrote many years ago a book about the importation of technological hazards by the petrochemical industry in Bahia, Brazil, arguing that if the U.S exported hazards to developing countries, the latter imported the hazards. In other words, if a country exports, another one imports. Thus, if Brazil exported part of its reserve army of labor to the U.S., the U.S. imported Brazilian cheap labor to fulfill for the most part the demand of the 
service and construction sectors. Scholars of Brazilian e/immigration documented that since the late 1980's Brazilian immigrant workers have delivered pizzas, cleaned houses, built and renovated condominiums, or staffed commercial and business offices. For decades now they have worked in insecure, unsafe, low-wage jobs without health or other common employee benefits, such as vacations and sick leave. Despite earning low wages in El Norte, most are happy to have a job that pays more than the ones in Brazil. Nevertheless, to make ends meet, pay debts, and send remittances home, many work long hours, in two or three jobs, and have very limited time to rest or enjoy life the same way they did in their states of origin (e.g. Minas Gerais, São Paulo, Santa Catarina, or Espírito Santo). As I've heard many times over, Brazilian immigrants think that in Brazil "one works to live" while in the U.S "one lives to work."

In addition, the contexts of expulsion and reception changed dramatically over the last thirty years, adding insult to injury. Scholars also tend to agree that migratory flows from the Global South to the Global North can be explained by a combination of political, social, and economic forces that interact dynamically in sending and receiving countries. Thus, while in the late 80's it was relatively easy for Brazilian immigrants to settle in the U.S. as undocumented workers, it became much harder to do it after the $9 / 11 / 2001$ attacks. The already high levels of stress faced by immigrants increased significantly when the federal Immigration Customs Enforcement (ICE) and local law enforcement targeted for deportation Brazilian as well as undocumented immigrants from all over the world. The Bush and Obama administration deported thousands of undocumented immigrants during the 2000's. The current Trump administration follows the same trend. Cyclical crises in both the U.S and Brazilian economies also produced marked shifts in the direction of Brazilian migration flows. While in the 80's the flow was directed towards the U.S., the Great Depression of the late 2000's reversed it towards Brazil. More recently, the flow appears to be like the one in the 80 's.

After this brief summary of Brazilian e/immigration I will address the main adverse health impacts identified and their potential association with e/ immigration issues. First, there are consistent findings from quantitative and qualitative studies that show a high prevalence of mental distress among Brazilian immigrants, usually expressed clinically as mild to severe depression and anxiety. Religious leaders, the Brazilian General Consulate in Massachusetts, and community leaders have been concerned with this issue for a long time now. It seems that conditioning factors to such mental health issues include social isolation, poor integration into U.S. society, chronic fear, lack of access to mental health care services, and stressful working conditions.

Second, surveys and observations of hundreds of workers found a variety of symptoms and signs associated with poor working conditions, such as back and neck pain, pain in the arms and legs (symptoms of musculoskeletal disorders), fatigue, traumatic injuries from falls, sleep disorders, irritability, skin rashes, among others. Third, a small but preventable number of deaths on the job have occurred in particular in the construction sector. Detailed analysis of several of these fatalities revealed that they were caused by unsafe work environments, where employers did not follow basic safety and health rules and regulations. Undocumented status did certainly contribute to the lack of protection afforded to Brazilian immigrant workers.

The acculturation process may be a universal source of stress and uneasiness to Brazilians in the U.S. because it demands a wide variety of cognitive, social, and psychological skills and resources, such as language skills, knowledge of U.S. culture, and ability to network and cope with stress. Short-term immigrants or sojourners need these resources to survive while long-term immigrants or settlers need them to integrate into U.S. society. As Brazilian immigrants acculturate to the U.S. they tend to adopt the normal, mainstream American lifestyle: they eat fast food, do not exercise regularly, and lack strong social networks. The longer they stay in the U.S. the more likely it is that they become American, which implies that they slowly develop a similar risk and health profile. For example, while there is no solid evidence about the prevalence of chronic diseases among Brazilians in the U.S., health providers who care for Brazilian patients suggest that the prevalence of diabetes and obesity is growing among those who settled in the U.S. More 
research needs to be done to confirm this hypothesis.

The view expressed by Brazilian immigrants that they moved from "work to live" in Brazil to "live to work" in the U.S. may reflect a fundamental wisdom about their migration trajectory: whereas in Brazil they live as citizens, in the U.S they live as workers. In Brazil, they speak the language, have families and long-term friends, know the culture, the basic history of the country, and are very familiar with their racial and class identities. After work, most do have a networked social life. In the U.S., they have to learn English, a foreign culture, and a foreign history; they usually do not have families nor long-term friends, nor do they fit easily into the racial, ethnic, and class identities accepted by American society. Thus, after work it is very difficult for them to have a social life!! Tom Jobim once expressed a similar idea, when he assumedly said: To live in a foreign country [US] is good, but it sucks. To live in Brazil sucks, but it is good."

\section{REFERENCES}

1. Siqueira CE, Jansen T. Updating Demographic, Geographic, and Occupational Information on Brazilian Immigration to the United States: The Case of Massachusetts. In: Jouët-Pastré C and Braga LJ (eds) Becoming Brazuca: Brazilian Immigration to the U.S. Cambridge: Harvard University Press; 2008. P. 105-124

2. Siqueira, CE, Roche AG. Occupational Health Profile of Brazilian Immigrant

Housecleaners in Massachusetts. New Solut. 2013;23(3):505520

3. Margolis, ML. Goodbye, Brazil: Émigrés from the Land of Soccer and Samba. Madison, Wisconsin: University of Wisconsin Press; 2013 